\title{
Partnering for Greater Success: Local Stakeholders and Research in Tropical Biology and Conservation
}

\author{
Karen A. Kainer ${ }^{1,2,6}$, Maria L. DiGiano ${ }^{3}$, Amy E. Duchelle ${ }^{2}$, Lúcia H. O. Wadt ${ }^{4}$, Emilio Bruna ${ }^{1,5}$, and Jonathan L. Dain ${ }^{1}$ \\ ${ }^{1}$ Center for Latin American Studies, University of Florida, PO Box 115530, Gainesville, FL 32611-5530, U.S.A. \\ ${ }^{2}$ School of Forest Resources and Conservation, University of Florida, PO Box 110410, Gainesville, FL 32611-0410, U.S.A. \\ ${ }^{3}$ School of Natural Resources and the Environment, Gainesville, PO Box 116455, Gainesville, FL 32611-6455, U.S.A. \\ ${ }^{4}$ Centro de Pesquisa Agroflorestal do Acre (Embrapa Acre), Caixa Postal 321, Rio Branco, Acre 69908-970, Brazil \\ ${ }^{5}$ Department of Wildlife Ecology and Conservation, University of Florida, PO Box 110430, Gainesville, FL 32611-0430, U.S.A.
}

\begin{abstract}
Local communities are important stakeholders in resource management and conservation efforts, particularly in the developing world. Although evidence is mixed in suggesting that these resident stakeholders are optimal forest stewards, it is highly unlikely that large tracts of tropical forests will be conserved without engaging local people who depend on them daily for their livelihoods. Stakeholders, who reside in biodiverse ecosystems like tropical forests, are the largest direct users and ultimate decisionmakers of forest fate, can be important investors in conservation, harbor local ecological knowledge that complements Western science and frequently have long-term legitimate claims on lands where they reside. Research partnerships with local stakeholders can increase research relevance, enhance knowledge exchange and result in greater conservation success. Different phases of the research cycle present distinct opportunities for partnership, with flexibility in timing, approaches and strategies depending on researcher and local stakeholder needs and interests. Despite being the last step in the research process, dissemination of results can be the best starting point for researchers interested in experimenting with local stakeholder engagement. Still, tropical biologists might not choose to partner with local people because of lack of institutional rewards, insufficient training in stakeholder engagement, insecure research infrastructure in community settings, and time and funding limitations. Although not appropriate in all cases and despite significant challenges, some biological scientists and research institutions have successfully engaged local stakeholders in the research process, proving mutually beneficial for investigators and local people alike and resulting in important innovations in tropical biology and conservation.
\end{abstract}

Abstracts in Spanish and Portuguese are available at http://www.blackwell-synergy.com/loi/btp.

Key words: community; dissemination; participatory research; returning results.

THE NEED FOR TROPICAL BIOLOGY AND CONSERVATION to be more inclusive of people and human activities is indisputable. The largest professional society of tropical biologists has expanded their mission to reflect these 21 st-century realities, clearly articulating the need to move 'beyond paradise'-beyond the vision of protecting an undisturbed wilderness to one that more fully embraces humans as integral components of tropical ecosystems (Association for Tropical Biology and Conservation [ATBC] 2004). While their primary research focus will continue to be biodiversity and ecosystem function, tropical biologists are now expected 'to actively assist in developing action plans for long-term conservation, use, and management of tropical landscapes' (ATBC 2004). This updated mission requires integration of the broader set of values and concerns held by rural people, adoption of interdisciplinary and participatory approaches that embrace a larger community of social scientists and rural communities, and enhanced linkages between science and policy (ATBC 2004). While there is consensus that this shift needs to occur, there are many challenges to moving beyond disciplinary foundations in the biological sciences to more effectively address human needs and interests. Societal engagement needs to occur at multiple levels to develop systems that sustain

Received 29 July 2008; revision accepted 21 January 2009.

${ }^{6}$ Corresponding author; e-mail: kkainer@ufl.edu global biodiversity and human well-being. In this paper, we focus on efforts to integrate research and the exchange of knowledge with local people living in and around tropical ecosystems, particularly in tropical forests. Although evidence is mixed in suggesting that these resident stakeholders are optimal forest stewards (Agrawal \& Gibson 1999), it is highly unlikely that large tracts of tropical forests will be conserved without engaging the local people who depend on them for their livelihoods (Scherr et al. 2002). We aim to illustrate not only why research partnerships with local people often make sense, but also share some strategies for integration of local stakeholders into the research process and institutionalization of these efforts.

\section{WHY PARTNER WITH LOCAL PEOPLE?}

LARGEST DIRECT USERS AND ULTIMATE DECISION-MAKERS.- - Rural communities are the largest direct users of tropical forests. Forests yield food, construction materials, medicines, fuel, as well as local ecosystem services such as flood control, soil enrichment and stabilization-all critical to sustain and improve rural livelihoods. In addition to this practical supply of local goods and services, forestdwelling people often value forests for cultural, ancestral and spiritual factors more elusive to quantification.

Their close proximity to tropical forests also means that local people frequently exercise final, on-the-ground decisions about 
forest fate. Although influenced by an array of extra-local drivers (Kaimowitz \& Angelsen 1998, Wood 2002, Chomitz et al. 2007), they are often the ultimate decision-makers, determining whether forests will be converted (or not) and whether resources will be used sustainably (or not) (Shackleton et al. 2009). If other levels of society did not consider tropical forests important, this local influence might not be contested. Tropical forests, however, provide innumerable products and services appreciated at larger regional, national and international scales, including timber and nontimber forest products and multiple ecosystem services such as biodiversity conservation, carbon storage and sequestration, and watershed protection. Most recently, the crucial role of tropical forests in global climate regulation has captured international scientific and public attention; almost 20 percent of all greenhouse gases originate from tropical deforestation (Stern 2006).

SigNIFICANT OWNERSHIP AND CONTROL.-Increasingly, local de facto influence over tropical forest fate is turning into legal authority. Almost 25 percent of all tropical forests are currently owned or legally managed by local communities (White \& Martin 2002). This proportion represents a doubling of the previous 15 -yr total, and is expected to double again in the next $15 \mathrm{yr}$ as decentralization and devolution of public forests to local control proceed (Molnar 2003). These devolution and decentralization efforts have been motivated by various political, economic and social factors. For example, it has been suggested that governments rarely have the resources to monitor and regulate vast forest expanses or the ability to manage them effectively. Economic arguments in favor of decentralization and devolution have centered on restructuring ownership systems (or land tenure) to encourage greater economic efficiency and attract foreign investment. Social movements, over decades and across the globe, have made successful claims that local people substantially contribute to forest management and conservation, and therefore should be granted rights of access and control of resource-rich areas (Campos \& Nepstad 2006, Cronkleton et al. 2008). Human rights organizations have also raised ethical arguments when protesting displacement of local people to create national parks and other conservation units. The bottom line, however, is that local people not only inhabit spaces we are trying to conserve, but also have significant rights and perhaps motivations to be considered potential conservation partners (Vermeulen \& Sheil 2006, Sunderland et al. 2007).

INVESTORS IN CONSERVATION.-Some studies have highlighted the abilities of local groups to maintain or increase tropical forest cover in countries like Nepal (Guatam et al. 2002), Mexico (Bray et al. 2004), Indonesia (Sheil \& Boissière 2006) and Brazil, even in the face of acute agricultural expansion (Nepstad et al. 2006). This is not meant to suggest that all communities have the ability or desire to halt deforestation or increase forest cover within their domain. In fact, local control may not be enough to conserve forests when economic benefits of conversion outweigh forest conservation values (Wunder 2000). However, research does indicate that some are investing their time, labor and financial resources in these activities. Molnar $e t$ al. (2007) estimate that rural communities dedicate between US $\$ 1.5$ and
US $\$ 2.5$ billion per year to forest conservation and management, an annual amount approximately equal to protected area budgets in developing countries. These estimates of community investment are derived from data on cash expenditures and in-kind labor directed to activities such as fire control, guarding land and resources, biological monitoring and habitat restoration (Molnar et al. 2007).

COMPLeMENT to WeStern SCIENCE.-Local people know resources in ways scientists and off-site managers typically do not (Moller et al. 2004, Chalmers \& Fabricius 2007; Table 1). Western science, which generates knowledge through strict and universally agreed-upon rules, is the conventional source of information for almost all formalized forest management. This approach contrasts with local ecological knowledge, which is generated on site by trial and error and is often cumulative, passed down through generations to explain relationships between humans and their environment. Engaging local experts, combining methods and exchanging information and insights generated by these different knowledge systems can lead to more effective working partnerships between local people and outsiders to comanage forests, a joint management approach that is gaining currency in practice (Moller et al. 2004, Charnley \& Poe 2007, Shackleton et al. 2009).

INCREASE RESEARCH RELEVANCE TO LOCAL REALITIES.-Research carried out in conjunction with local people, close to the resource, has

TABLE 1. Comparison of two knowledge systems: Local ecological knowledge and Western science.

\begin{tabular}{|c|c|}
\hline Local ecological knowledge & Western science \\
\hline $\begin{array}{l}\text { Temporal depth across generations } \\
\text { with a rare historical perspective. }\end{array}$ & Studies are usually short-term. \\
\hline $\begin{array}{l}\text { Knows local site, but less likely to } \\
\text { understand how it relates to larger } \\
\text { spatial patterns and processes. }\end{array}$ & $\begin{array}{l}\text { Can attain spatial breadth that may } \\
\text { link local site to larger spatial scales, } \\
\text { particularly with new technologies. }\end{array}$ \\
\hline $\begin{array}{l}\text { Ability to understand and relate local } \\
\text { resource changes and land use } \\
\text { outcomes to observed, complex } \\
\text { social and ecological influences. }\end{array}$ & $\begin{array}{l}\text { Ability to monitor and predict large- } \\
\text { scale processes and drivers that } \\
\text { escape local observation. }\end{array}$ \\
\hline $\begin{array}{l}\text { Ability to observe and record } \\
\text { unusual occurrences and extremes. }\end{array}$ & $\begin{array}{l}\text { Tendency to focus on averages and } \\
\text { patterns. Unusual events may be } \\
\text { considered outliers. }\end{array}$ \\
\hline $\begin{array}{l}\text { Integrated or holistic understanding } \\
\text { that may recognize spiritual and } \\
\text { cultural dimensions. }\end{array}$ & $\begin{array}{l}\text { Tendency to break things down into } \\
\text { parts for in-depth understanding; } \\
\text { however, integration of natural and } \\
\text { social sciences helps incorporate } \\
\text { spiritual and cultural dimensions. }\end{array}$ \\
\hline $\begin{array}{l}\text { Rapid and inexpensive gathering of } \\
\text { qualitative information, but } \\
\text { perhaps lacks quantitative precision. }\end{array}$ & $\begin{array}{l}\text { Focus on obtaining and analyzing } \\
\text { numerical data. Precise with what } \\
\text { examined. Often costly. }\end{array}$ \\
\hline $\begin{array}{l}\text { Intimate involvement may better } \\
\text { position local people to identify } \\
\text { problem-oriented hypotheses and } \\
\text { questions. }\end{array}$ & $\begin{array}{l}\text { Focus on identifying theoretical } \\
\text { hypotheses and questions coupled } \\
\text { with powerful tools for testing why. }\end{array}$ \\
\hline
\end{tabular}


a greater chance of being relevant to local realities and needs. Partnering makes it more likely that local people will take ownership of research results, whether obtained through experimentation or observation. As local people increase their knowledge and direct experience with the scientific research process, results will be better understood. Similarly, when encouraged to reach their own conclusions, local people are more likely to accept them (Sheil \& Lawrence 2004) and apply them in management decisions.

Relative numbers and Permanence on landscape.-White and Martin (2002) estimate that 400-500 million nonindigenous people directly depend on tropical forests for their livelihoods, in addition to the approximately 60 million indigenous people who reside in tropical rain forests. Based on these numbers and their relative permanence on the landscape, partnering in conservation and conservation research, although certainly not without challenges, seems imminently logical (Campos \& Nepstad 2006). Partnering specifically with those living close to protected areas offers an additional opportunity to effectively expand park boundaries (Bawa 2006). People living in and around protected areas will likely remain there long after research projects end, after governments change hands and after scientists leave. Time horizons dictated by grant cycles limit effectiveness of many well-intentioned conservation projects (Bawa 2006) while joint learning between scientists and local people through research and other discovery processes may facilitate improved management that will last longer than project cycles.

LONG-TERM LEGITIMATE CLAIMS.-In addition to the above efficiency arguments, there are also ethical reasons to integrate local stakeholders into tropical research projects. While many tropical forest benefits accrue at higher transnational and global scales (i.e., biodiversity conservation, carbon storage and sequestration), the costs of maintaining them are disproportionally borne at lower national and regional scales, with the largest burden typically felt at the local level (Wells 1992). Communities attempting to address their own livelihood needs are often expected to attend to additional, much broader international forest conservation objectives. It seems only fair that tropical forest research agendas, which are typically set at national if not international levels, should be determined with input from those who have resided in the forest for generations and increasingly aspire to (and are expected to) manage their forest ecosystems with greater economic and ecological sophistication.

\section{STRATEGIES FOR EFFECTIVE LOCAL PARTNERSHIPS}

If research partnerships with local communities are accepted as an important strategy of tropical conservation and restoration efforts (ATBC 2004), how can we go about developing them? How can we integrate rural communities and their support organizations into the research process and enhance knowledge exchange? Lessons from predecessors focused on tropical agricultural research and community forestry can help inform this expanded research mission.
LEARNING FROM PREDECESSORS.-Over the past four decades, researchers and research institutions have developed and tested diverse approaches and methods for partnering with rural people to improve agricultural and forest-based livelihoods. The Green Revolution of the 1960s, which produced new high-yielding grain varieties, resulted in tremendous advances in food production across the globe, but tended to favor only those farmers who were already in relatively advantageous positions (Whyte 1986). The rural majority, small-scale, resource-limited farmers who were largely passed over by the Green Revolution, began to receive some attention in the 1970s with the publication of Schumacher's (1973) Small is Beautiful and subsequently World Neighbors' Two Ears of Corn (Bunch 1982). Conceptual and practical approaches to research also emerged with an emphasis on 'farmer first' (Chambers 1983, Chambers et al. 1989) and the Farming Systems Research and Extension (FSRE) approach (Hildebrand 1981, 1986). These new perspectives were highly innovative not only in their focus on smallholders, but also in their assumption that farmers should be partners in research endeavors to design and evaluate new technologies (Ashby 1990a, b). These scientists advocated 'on-farm' research, arguing that conducting experiments with farmers in situ, despite the risks and potential loss of experimental control, greatly improved the speed, science and application of agricultural advancement. FSRE practitioners also developed methods that allowed multidisciplinary teams of scientists to engage in joint research activities, seeking to understand the farm as a complex, interconnected system rather than a series of isolated farm components defined by disciplinary lenses (Hildebrand \& Waugh 1986). These early experiences in interdisciplinarity (Rhoades 1984) underscored the tremendous benefits of strong research collaborations between biologists and social scientists, a benefit still considered so vital today that it is embedded in one of three guiding principles for tropical biologists (ATBC 2004).

The FSRE approach also highlighted the importance of the household as the central decision-making unit of the farming system (Poats \& Feldstein 1989). Over time, the assumed homogeneity of the farm household was dispelled as gendered differences in household roles and their impact on resource use decisions became evident (Overholt et al. 1985). These themes of participation, gender and people-centered research have more recently been extended to natural resource management and community forestry (Arnold 1992, Thomas-Slayter et al. 1993, Food and Agriculture Organization of the United Nations 1999). Fresh methodological advancements through the Center for International Forestry Research (CIFOR) and others have more fully integrated fundamental issues of biodiversity, ecosystem services and ecological integrity with the livelihood concerns of forest-based and other natural resourcedependent groups (Wollenberg et al. 2000, Campbell \& Luckert 2002, Evans et al. 2006). Similarly, local ecological knowledge has also come to the fore when expanding to forest-focused rural people (Berkes et al. 2000). The hard-won lessons of these agricultural and forestry predecessors working in the developing world can serve tropical biologists well as they pursue their broader participatory and interdisciplinary research agenda in partnership with local stakeholders. 
INTEGRATION AND THE RESEARCH CYCLE.- - How might some of these strategies, tools and approaches be applied during the research cycle? There is now a relatively large body of academic and practitioner experiences with tropical resource management and conservation found under the rubric of 'participatory' or 'collaborative' research (Slocum et al. 1995, Evans et al. 2006, Lynam et al. 2007, Arnold \& Fernandez-Gimenez 2008). These research frameworks consider a continuum that ranges from nonparticipation to full partnerships, in defining research agendas, executing projects, interpreting, using and disseminating results (Castillo et al. 2005). One innovative book jointly evaluates the success of participatory research projects from the perspectives of both lead scientists and local collaborators - the latter being a voice rarely heard in the scientific literature. This dual reporting pushes the envelope of full partnership by effectively demonstrating differences in evaluation measures: complementary views of certain projects and contrasting views of others (Fortmann 2008). Our intent is not to thoroughly critique the details of engaging local people in the research process, but rather to highlight a few key opportunities within this process where biological scientists have and will continue to develop local research partnerships (Fig. 1).

The initial stage of research design, specifically development of research questions, is a key moment for engaging stakeholders in the research process. While not always possible or appropriate, partnering at this stage can build in greater research relevance, trust among partners and overall buy-in to the research project (Barnard et al. 2006). Similarly, local feedback at the research design phase on preconceived research ideas can help redirect or refine research to better meet the needs and realities of local contexts. For example, experimental treatments for silvicultural management may be redefined to integrate an already-practiced treatment or one that is more likely to be applied given local constraints. Finally, researcher-community partners should consider developing a cooperative research agreement whereby expectations, responsibilities and negotiated terms of collaboration are transparent (Firehock 2003). Thoughtful communication at the beginning will pay off throughout the collaborative process.

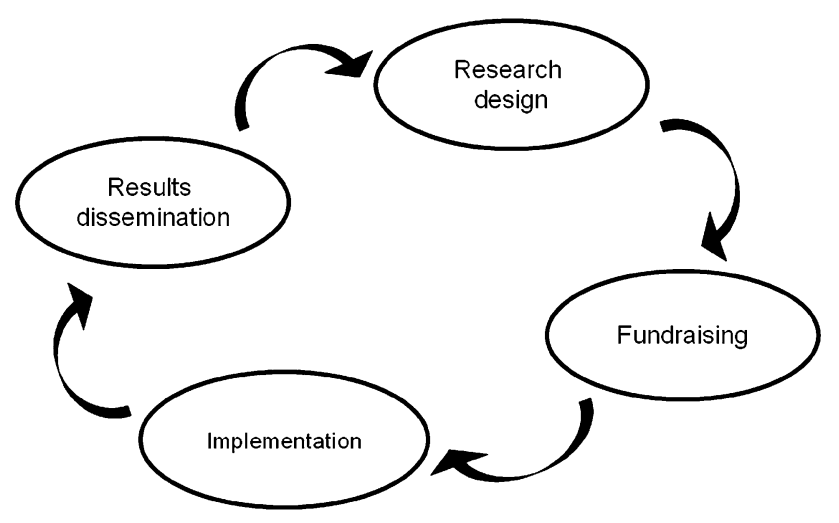

FIGURE 1. Phases of the research cycle. Each phase presents distinct opportunities for partnership, with flexibility in timing, approaches and strategies depending on researcher and local stakeholder needs and interests.
Fundraising for ecological research is always a concern, and inclusion of local people when setting research agendas certainly complicates matters. Nonetheless, explicit inclusion of local capacity building, dissemination of results and other types of partner engagement activities can be advantageous in making the case for research funding. The U.S. National Science Foundation (2007) emphasizes 'broadening participation of underrepresented groups', 'enhancing networks and partnerships' and 'disseminating results broadly to enhance scientific and technological understanding'. Field grant applicants for the doctoral dissertation research abroad field grants sponsored by the U.S. Department of Education Fulbright Hays Program must demonstrate appropriate contacts and affiliations abroad as well as plans to share research results with host-country scholars and officials. Insertion of budgetary lines to fund activities that attend to local partner needs, including attention to direct resource users, as related to the project, even if they are not completely funded, can go a long way to strengthening researcher-community relations. Formal partnerships are also required for granting of research visas to foreigners in many tropical countries.

Implementation, from data collection to interpretation, is another phase of research in which local stakeholders might be effectively integrated. Concerns over data quality can be a concern to tropical biologists engaged in collaborative projects. However, recent experiences with the use of parataxonomists-field-based inventory specialists who are usually residents in the ecosystem studied-have been largely positive, finding that these 'specialists' have been cited as key assets in tropical conservation (Basset $e t$ al. 2004, Janzen 2004, Sheil \& Lawrence 2004). Continued refinement of the limitations and applications of parataxonomy coupled with solutions for improving the consistency of species identification show great promise (Baraloto et al. 2007). Researcher interactions with local people during data collection may also provide day-to-day opportunities for debate over observations, findings and interpretation of results (Parrado-Rosselli 2007). For scientists who can successfully partner with local stakeholders during research implementation, the rewards can involve in-depth knowledge exchange and interpretation of findings from diverse perspectives that can strengthen understanding of tropical ecosystems and build more sustainable conservation strategies.

Results dissemination is likely the research phase where scientists can most readily integrate local stakeholders into the research process. While dissemination comes at the end of the research process, it may be a logical first step for researchers interested in experimenting with local stakeholder engagement. The extension of ecological findings can take on various formats including interactive workshops, extension pamphlets, manuals, school curricula, radio, field visits and more (Shanley et al. 1996, Shanley 1998, Shanley \& Laird 2002). The dissemination phase also provides an opportunity to thank local people for their engagement in the research process. Simple gestures such as presenting certificates of participation or holding community celebrations can reinforce the give and take needed to foster genuine partnerships between scientists and local stakeholders. In both dissemination of results and giving closure to the research process, scientists are only constrained by their creativity. 


\section{WHAT HOLDS US BACK?}

There are multiple reasons why tropical biologists might not choose to engage with local people. Below, we highlight some of the difficulties in harmonizing distinct local and scientific agendas, as well as how some of these challenges might be confronted through institutionalization and other means.

Not APpropriate IN ALL CASES.- - Some tropical research is less applicable to local people and their management systems than others. Does a scientist constructing a molecular phylogeny of dragonflies need to develop his/her research questions in collaboration with communities? Some kinds of science clearly do not benefit from local engagement, and can be efficiently executed without this type of local partnership. However, much can be gained from explaining the objectives and outcomes of such research to local communities. In addition to establishing positive relationships with community members who might one day host future researchers, transparency regarding specimen collection and the motivation for conducting such research can help assuage concerns about access to biological or cultural patrimony.

LACK OF FACILITIES.-Even if science can benefit by embedding a research project in a community-managed forest or locally run conservation unit, there will likely be less infrastructural and logistical support to execute research. Internet access, detailed soils maps and the accumulated body of knowledge that comes from working in a well-established research station will be lacking. Also absent will be a group of scholars with specialized scientific expertise, although they may find 'in-community' collaborators with a wealth of ecological knowledge that complements their own. Linkages with local universities and research groups can also alleviate some of these challenges, but there are clearly trade-offs in conducting research 'on-station' vs. 'in-community'. Two innovative tropical research centers have reconciled some of these trade-offs by creating spaces that foster high-quality scientific research and joint learning in conjunction with local stakeholders: Ashoka Trust for Research in Ecology and the Environment (ATREE) in India and the Institute for Ecological Research (IPE) in Brazil. Such institutes adopt the regional landscape as their research sites, integrate university training and research directly into their programs, and simultaneously engage local stakeholders in highly successful conservation/sustainable development partnerships.

REQUIRES ADDITIONAL RESOURCES.-Engaging local stakeholders at any degree of intensity is time consuming and may require extra funding. As Shanley and López (2009) point out; donors must be on board if research in tropical biology and conservation is to be significantly expanded to integrate local stakeholders. This notwithstanding, one only has to look as far as IPE and ATREE to see unquestionable evidence that donors are interested in investing in successful collaborative research and action partnerships.

UNCERTAIN FUTURE FOR FIELD SITES.-Linked to these trade-offs, there is potentially greater risk in investing in a research site that lacks the security of a biological station or formal protected area. Losing a precious replicate, or even an entire experiment, to cattle herbivory or escaped fire is a legitimate concern, and establishing long-term studies can be a risky proposition. Early and continuing investment in community relations, including shared responsibilities and benefits, can alleviate some of these risks - the more knowledgeable and vested local people are in the research, the greater the security of the research endeavor.

LACK OF INSTITUTIONAL REWARDS.-Until the engagement of local stakeholders is considered part of research, tropical biologists are less likely to invest in local collaborative partnerships. Many scientists in academia have found that engaging local communities in science is not typically rewarded (Barnard et al. 2006, Shanley \& López 2009); furthermore, potentially lower productivity (as currently defined in academic circles) resulting from the challenges described above may even hinder professional advancement (Shanley \& López 2009). Scientists rarely receive significant institutional credit for research products such as manuals or locally oriented education materials that are not peer reviewed. It is no surprise, therefore, that many tropical researchers consider information transfer a separate and perhaps lower endeavor (Shanley \& Laird 2002). It is logical to consider the scientific process complete once findings are published in scientific journals; indeed refereed publications are central to fundraising and career advancement (Shanley \& Laird 2002).

This aspect of scientific culture, however, is being challenged in some circles (Shanley \& López 2009). On the one hand, scholars fearful of an overemphasis on 'career assessment by numbers' (Kelly \& Jennions 2006) are critically examining the growing popularity of impact factors and the h-index, questioning if 'institutions have a misguided sense of the fairness of decisions reached by algorithm' (Lehmann et al. 2006). On the other hand, universities, particularly those with a mandate to solve stakeholder problems, and research institutions such as CIFOR are increasingly attempting to integrate measures of research impact on target stakeholders (Sunderland et al. 2009). Considering the next generation of tropical researchers, graduate training programs are attempting to institutionalize hostcountry partner engagement by linking student academic credits and field research funding to engagement of local people (Duchelle et al. 2009).

Do NOT KNOW HOW.- The outlook and skills necessary to engage communities are often not found in organizations that collect and analyze scientific data (Shanley \& Laird 2002). Tropical researchers are trained in modern scientific methods and perhaps local languages, not the engagement of stakeholders. Similarly, collaborative research methods are not as well known to biological scientists. During formative graduate training, few courses are offered in which students can garner skills in information exchange, group facilitation and negotiation with partners (although see Duchelle et al. 2009). And even if courses are offered, they are generally viewed as extracurricular and tacked on to an already heavy course load. Notwithstanding, methods and approaches for partnering in research with rural people have been developed 
by predecessors, and are growing. Furthermore, research protocols have been developed that lay out clear guidelines for ethical and effective research within community-based collaborative projects (Firehock 2003).

MAY BE UNCOMFORTABLE.-Finally, collaborating with local people may take scientists out of their comfort zone. The intellectual tendency of tropical researchers to stay firmly grounded in their biological roots is comforting (Robinson 2006), while the idea of nurturing different relationships and networks, possibly with groups critical and perhaps suspicious of researchers, is daunting. New languages and cultures can also create discomfort; for nonnatives, an imperfect grasp of the local language can make communication difficult, while for host-country nationals, local dialects, speech patterns and ethnic, gender and class divisions can make interactions awkward. Even disseminating research findings to local stakeholders is not without risks, as results can be challenged, misinterpreted and even co-opted to pursue other agendas (Barnard et al. 2006). This can make researchers, who are usually exceptionally cautious in their research interpretations and pronouncements, uncomfortable. Nonetheless, some biologists are learning by doing, gradually becoming comfortable with the ambiguities of conducting research with local stakeholders. Parrado-Rosselli (2007) describes an incremental process whereby the research relationship with a Colombian indigenous group grew increasingly collaborative over time, ultimately resulting in better understanding of fruit availability and seed dispersal and more sustained conservation efforts at the local level. The growing numbers of refereed publications and Special Issues such as this one that relate similar experiences are evidence that sectors of the scientific community are comfortable with and value collaborative research partnerships with local stakeholders.

\section{CONCLUSIONS}

Although not without challenges, we believe that when appropriate, engaging local stakeholders in the scientific research process has the potential to be mutually beneficial for investigators and local people, and can result in important innovations in tropical biology and conservation. Institutionalization of these approaches may be critical to helping researchers interested in engaging local people overcome some of these challenges. These include research centers such as ATREE and IPE who at their core bridge scientific research and training with direct engagement of local stakeholders; graduate education programs that train and encourage upcoming scientists how to form collaborative partnerships with local stakeholders; some evidence of change in donor culture; and recent publications of participatory research tools and experiences in tropical biology and conservation that provide guidance. Tropical biologists who are interested in engaging local people, however, need not wait for institutional and cultural change before experimenting with their own brand of partnerships with local stakeholders.

\section{ACKNOWLEDGMENTS}

We gratefully acknowledge the invitation and challenge laid out by symposium organizers to the 2007 Annual Meeting of the Association of Tropical Biology and Conservation (ATBC) in Morelia, Mexico. They inspired us to address the 'limited practical transfer of the immense scientific research output to local communities' and other decision-makers. We also thank our many research colleagues, on paper and in person, who have stimulated our creativity and challenged our thinking of community-based research partnerships. Anonymous reviewers also improved this manuscript and we thank Diana (Tita) Alvira for the Spanish language translation of the abstract. Finally, we are most grateful to the many local stakeholders who have engaged us in their experiments, shared their observations and challenged us to be better scientists.

\section{LITERATURE CITED}

Agrawal, A., And C. C. Gibson. 1999. Enchantment and disenchantment: The role of community in natural resource conservation. World Dev. 27: 629-649.

ARnOlD, J. E. M. 1992. Community forestry: Ten years in review (revised edition). Food and Agriculture Organization of the United Nations, Rome, Italy.

Arnold, J. S., and M. E. Fernandez-Gimenez. 2008. Engaging communities through participatory research. In E. M. Donaghue and V. S. Sturtevant (Eds.). Forest community connections: Implications for research, management and governance, pp. 66-87. Resources for the Future, Washington, District of Columbia.

Ashby, J. 1990a. Evaluating technology with farmers: A handbook. Centro International de Agricultura Tropical, Cali, Colombia.

Ashby, J. 1990b. Small farmers' participation in the design of technologies. In M. A. Altieri and S. B. Hecht (Eds.). Agroecology and small farm development, pp. 245-253. CRC Press, Boca Raton, Florida.

Association for Tropical Biology and Conservation (ATBC). 2004. Beyond paradise-Meeting the challenges in tropical biology in the 21 st century. ATBC, Washington, District of Columbia.

Baraloto, C., E. Ferreira, C. Rockwell, and F. Walthier. 2007. Limitations and applications of parataxonomy for community forest management in southwestern Amazonia. Ethnobot. Res. Appl. 5: 77-84.

Barnard, G., L. Carlile, and D. B. Ray. 2006. Maximising the impact of development research: How can funders encourage more effective research communication? International Institute for Environment and Development (IIED), London, UK.

Basset, Y., V. Novotny, S. E. Miller, G. D. Weiblens, O. Missa, and A. J. A. STEWART. 2004. Conservation and biological monitoring of tropical forests: The role of parataxonomists. J. Appl. Ecol. 41: 163-174.

BAWA, K. S. 2006. Globally dispersed local challenges in conservation biology. Conserv. Biol. 20: 696-699.

Berkes, F., J. Colding, And C. Folke. 2000. Rediscovery of traditional ecological knowledge as adaptive management. Ecol. Appl. 10: 1251-1262.

Bray, D. B., E. A. Ellis, N. Armijo-Canto, and C. T. Beck. 2004. The institutional drivers of sustainable landscapes: A case study of the "Mayan Zone” in Quintana Roo, Mexico. Land Use Policy 21: 333-346.

Bunch, R.. 1982. Two ears of corn: A guide to people-centered agricultural improvement. World Neighbors, Oklahoma City, Oklahoma.

Campbell, B., ANd M. LucKert (Eds.). 2002. Uncovering the hidden harvest: Valuation methods for woodland and forest resources. Earthscan, London, UK.

Campos, M. T., and D. C. Nepstad. 2006. Smallholders, the Amazon's new conservationists. Conserv. Biol. 20: 1553-1556. 
Castillo, A., A. Torres, A. Velázquez, and G. Bocco. 2005. The use of ecological science by rural producers: A case study in Mexico. Ecol. Appl. 15: 745-756.

Chalmers, N., AND C. Fabricius. 2007. Expert and generalist local knowledge about land-cover change on South Africa's wild coast: Can local ecological knowledge add value to science? Ecol. Soc. 12: 10. Available at http://www.ecologyandsociety.org/vol12/iss1/art10/

Chambers, R. 1983. Rural development: Putting the last first. Longman, Harlow, UK.

Chambers, R., A. Pacey, and L. A. Thrupp (Eds.). 1989. Farmer first: Farmer innovation and agricultural research. Intermediate Technology Publications, London, UK.

Charnley, S., And M. R. Poe. 2007. Community forestry in theory and practice: Where are we now? Annu. Rev. Anthropol. 36: 301-336.

Chomitz, K. M., P. Buys, G. De Luca, T. S. Thomas, and S. WertzKanOunNiKOfF. 2007. At Loggerheads? Agricultural expansion, poverty reduction, and environment in the tropical forests. World Bank, Jakarta, Indonesia.

Cronkleton, P., P. L. Taylor, D. Barry, S. Stone-Jovocich, and M. SchMINK. 2008. Environmental governance and the emergence of forestbased social movements. CIFOR Occasional Paper No. 49, Center for International Forestry Research (CIFOR), Bogor, Indonesia.

Duchelle, A. E., K. Biedenweg, C. Lucas, A. Virapongse, J. Radachowsky, D. J. Wojcik, M. Londres, W. Bartels, D. Alvira, and K. A. Kainer. 2009. Graduate students and knowledge exchange with local stakeholders: Possibilities and preparation. Biotropica 41: 578-585.

Evans, K. W. de Jong, P. Cronkleton, D. Sheil, T. Lynam, T. Kusumanto, AND C. J. P. COLFER. 2006. Guide to participatory tools for forest communities. Center for International Forestry Research (CIFOR), Bogor, Indonesia.

Food and Agriculture Organization of the United Nations. 1999. Community forestry publications. FAO, Rome, Italy.

FireHOCK, K. 2003. Protocol and guidelines for ethical and effective research of community based collaborative processes. Community Based Collaboratives Research Consortium, University of Virginia, Blacksburg, Virginia.

ForTMANN, L. 2008. Participatory research in conservation and rural livelihoods: Doing science together. Wiley-Blackwell, Chichester, UK.

Guatam, A. P., E. L. Webb, and A. Eiumnoh. 2002. GIS assessment of land use/ land cover changes associated with community forestry implementation in the Middle Hills of Nepal. Mt. Res. Dev. 22: 63-69.

Hildebrand, P. E. 1981. Combining disciplines in rapid appraisal: The sondeo approach. Agric. Admin. 8: 423-432.

Hildebrand, P. E. (Ed.). 1986. Perspectives on farming systems research and extension. Lynne Rienner Publishers, Boulder, Colorado.

Hildebrand, P. E., and R. K. Waugh. 1986. Farming systems research and development. In P. E. Hildebrand (Ed.). Perspectives on farming systems research and extension, pp. 12-15. Lynne Rienner Publishers, Boulder, Colorado.

JANZEN, D. H. 2004. Setting up tropical biodiversity for conservation through non-damaging use: Participation by parataxonomists. J. Appl. Ecol. 41: $181-187$.

Kaimowitz, D., AND A. Angelsen. 1998. Economic models of tropical deforestation-A review. Center for International Forestry Research (CIFOR), Bogor, Indonesia.

Kelly, C. D., And M. D. Jennions. 2006. The $h$ index and career assessment by numbers. Trends Ecol. Evol. 21: 167-170.

Lehmann, S., A. D. JaCKSON, AND B. E. LaUtrup. 2006. Measures for measures. Nature 441: 1003-1004.

Lynam, T., W. De Jong, D. Sheil, T. Kusumanto, and K. Evans. 2007. A review of tools for incorporating community knowledge, preferences, and values into decision making in natural resources management. Ecol. Soc. 12: 5. Available at http://www.ecologyandsociety.org/vol12/ iss $1 / \operatorname{art} 5 /$

Moller, H., F. Berkes, P. O. Lyver, And M. Kisliogliu. 2004. Combining science and traditional ecological knowledge: Monitoring populations for co- management. Ecol. Soc. 9: 2. Available at http://www.ecologyandsociety. org/vol9/iss3/art2/

MolnaR, A.. 2003. Forest certification and communities: Looking forward to the next decade. Forest Trends, Washington, District of Columbia.

Molnar, A., M. Liddle, C. Bracer, A. Khare, A. White, and J. Bull. 2007. Community-based forest enterprises in tropical forest countries: Status and potential. International Tropical Timber Organization, Forest Trends, and Rights and Resources Initiative, Washington, District of Columbia.

National Science Foundation. 2007. Merit review broader impacts criterion: Representative activities. NSF, Washington, District of Columbia.

Nepstad, D., S. Schwartzman, B. Bamberger, M. Santilli, D. Ray, P. Schlesinger, P. LeFebvre, A. Alencar, E. Prinz, G. Fiske, and A. Rolla. 2006. Inhibition of Amazon deforestation and fire by parks and Indigenous lands. Conserv. Biol. 20: 65-73.

Overholt, C., M. B. Anderson, K. Cloud, and J. E. Austin (Eds.). 1985. Gender roles in development projects: A case book. Kumarian Press, West Hartford, Connecticut.

Parrado-Rosselli, A. 2007. A collaborative research process studying fruit availability and seed dispersal within an Indigenous community in the Middle Caqueta River region, Columbian Amazon. Ecol. Soc. 12: 39. Available at http://www.ecologyandsociety.org/vol12/iss2/art39/

Poats, S. V., and H. S. Feldstein. 1989. Introduction. In H. S. Feldstein and S. V. Poats (Eds.). Working together: Gender analysis in agriculture, pp. 1-5. Kumarian Press Inc., West Hartford, Connecticut.

RHOADES, R. E. 1984. Breaking new ground: anthropology in agricultural research. International Potato Center, Lima, Peru.

Robinson, J. G. 2006. Conservation biology and real-world conservation. Conserv. Biol. 20: 658-669.

SCHERR, S. J., A. White, AND D. Kaimowitz. 2002. Making markets work for forest communities. Forest Trends, Washington, District of Columbia.

SCHUMACheR, E. F. 1973. Small is beautiful: Economics as if people mattered. Perennial Library, New York, New York.

Shackleton, C. M., G. Cundill, and A. T. Knight. 2009. Beyond just research: Experiences from southern Africa in developing social learning partnerships for resource conservation initiatives. Biotropica 41: 563-570.

SHANLEY, P. 1998. Extending ecological research to meet local needs: A case from Brazil. In T. C. H. Sunderland, L. E. Clark, and P. Vantomme (Eds.). Non-wood forest products of Central Africa: Current research issues and prospects for conservation and development, pp. 99-108. Food and Agriculture Organization of the United Nations, Rome, Italy.

Shanley, P., AND S. A. LAird. 2002. "Giving back": Making research results relevant to local groups in conservation. In S. A. Laird (Ed.). Biodiversity and traditional knowledge: Equitable partnerships in practice, pp. 102-124. Earthscan Publications Ltd., London, UK.

SHANLEY, P., AND C. López. 2009. Out of the loop: Why research rarely reaches policy-makers and the public_-and what can be done. Biotropica 41: 535-544.

Shanley, P., L. LuZ, J. Galvâo, and M. Cymerys. 1996. Translating dry data for forest communities: Science offers incentives for conservation. Rural Development Forestry Network Paper 19e, Overseas Development Institute, London, UK.

SHeIL, D., AND M. Boissière. 2006. Local people may be the best allies in conservation. Nature 440: 868 .

Sheil, D., And A. Lawrence. 2004. Tropical biologists, local people and conservation: New opportunities for collaboration. Trends Ecol. Evol. 19: 634-638.

Slocum, R., L. Wichhart, D. Rocheleau, and B. Thomas-Slayter (Eds.). 1995. Power, process and participation: Tools for change. Intermediate Technology Publications, London, UK.

Stern, N. 2006. The economics of climate change: The Stern review. Cambridge University Press, Cambridge, UK.

Sunderland, T., J. Sunderland-Groves, P. Shanley, and B. Campbell. 2009. Bridging the gap: How can information access and exchange between 
conservation biologists and field practitioners be improved for better conservation outcomes? Biotropica 41: 549-554.

Sunderland, T. C. H., C. Ehringhaus, and B. M. Campbell. 2007. Conservation and development in tropical forest landscapes: A time to face the trade-offs? Environ. Conserv. 34: 276-279.

Thomas-Slayter, B., A. L. Esser, and M. D. Shields. 1993. Tools of gender analysis: A guide to field methods for bringing gender into sustainable resource management. Program for International Development and Social Change, Clark University, Worcester, Massachusetts.

Vermeulen, S., and D. Sheil. 2006. Partnerships for tropical conservation. Oryx 41: 434-440.

WeLLS, M. 1992. Biodiversity, conservation, affluence and poverty: Mismatched costs and benefits and efforts to remedy them. Ambio 21: 237-243.
White, A., And A. MarTin. 2002. Who owns the world's forests? Forest Trends, Washington, District of Columbia.

Whyте, W. F. 1986. The need for a new strategy. In P. E. Hildebrand (Ed.). Perspectives on farming systems research and extension, pp. 1-12. Lynne Rienner Publishers, Boulder, Colorado.

WollenberG, E., D. Edmunds, And L. Buck. 2000. Anticipating change: Scenarios as a tool for adaptive forest management. Center for International Forestry Research (CIFOR), Bogor, Indonesia.

Wood, C. H. 2002. Land use and deforestation in the Amazon. In C. H. Wood and R. Porro (Eds.). Deforestation and land use in the Amazon, pp. 1-38. University of Florida Press, Gainesville, Florida.

Wunder, S. 2000. The economics of deforestation. The example of Ecuador. Macmillan, St. Antony's Series, Houndmills, UK. 